\title{
PROTECTION OF INTERNAL WELD USING A SILICATE COATING
}

\author{
E. A. Yatsenko ${ }^{1}$, A. V. Ryabova ${ }^{1}$, B. M. Goltsman ${ }^{1}$, V. A. Smoliy ${ }^{1}$ \\ ${ }^{1}$ Platov South Russian State Polytechnic University (Novocherkassk, Russia)
}

E-mail: e_yatsenko@mail.ru; annet20002006@yandex.ru; boriuspost@gmail.com; vikk-toria@yandex.ru

\section{A UTHOR'S I N FO \\ E. A. Yatsenko, Dr. Eng., Prof., Head of the Dept. "General Chemistry and Technology of Silicates" \\ A. V. Ryabova, Cand. Eng., Associate Prof., Dept. "General \\ Chemistry and Technology of Silicates" \\ B. M. Goltsman, Cand. Eng., Associate Prof., Dept. "General Chemistry and Technology of Silicates" \\ V. A. Smoliy, Cand. Eng., Associate Prof., Dept. "General Chemistry and Technology of Silicates"}

Key words:

weld, silicate coating, vitreous enamel, frit, assembly paste, corrosion protection, coating defects

\section{A B S T R ACT}

The main disadvantage of steel pipes and pipeline parts is their sensitivity to corrosion, which leads to a huge waste of metal and reduces the pipeline service life. In the past 15 years, the oil and gas industry has seen a drastic increase in the production of internally coated pipes and pipes made from corrosion-resistant materials. Therefore, their connection must have the same strength, pressure tightness and corrosion resistance as the material of a main pipe. The need to protect the weld is due to the weld and the connected area is the most vulnerable point in the structure. Therefore, the purpose of this work is to develop a technology for enameling the steel pipeline weld with an internal vitreous silicate enamel coating. The components were weighed, mixed and melted. The resulting frit is an X-ray amorphous glass phase. On the basis of the obtained frit, enamel slurries of the required fineness and composition were prepared and tested for the main rheological properties: density; covering ability (amount of slurry retained on a metal product surface); fineness of grinding (degree of frit grinding in slurry suspension); sedimentation stability (resistance of system particles to settling). Slurry was applied to the pretreated steel samples by pouring method. Then the samples were dried for 7-10 minutes at a temperature of 70-90 ${ }^{\circ} \mathrm{C}$. Fastening firing was carried out in an electric furnace in the temperature range of $750-950{ }^{\circ} \mathrm{C}$ for 5 minutes. The quality of the weld and the presence of defects were analyzed after cooling. The optimal composition was chosen. It is characterized by the following advantages: complete melting of the enamel; absence of "copper heads"; absence of bubble craters, as well as small bubbles in the enamel volume; absence of burnouts. Further, the main technical and operational properties of the protective coating for the pipe weld were investigated: chemical resistance to the acid and alkali solutions; "coating - metal" adhesion strength; wear resistance (abrasion resistance). The results obtained demonstrate high protection rates of the synthesized coating, its high durability and reliability.

\section{Introduction}

The main disadvantage of steel pipes and pipeline parts is their sensitivity to corrosion, which leads to a huge waste of metal, shortening the pipeline service life, increases the roughness of the pipe walls inner surface that leads to an additional energy consumption for fluid transportation. Thus, pipe corrosion leads to an increase in the construction and maintenance costs of fluid transportation systems.

A silicate enamel coating is used to protect the pipe inner surface from the aggressive corrosive and abrasive effects of the transported products. Such a coating can increase the pipe service life by up to 50 years. The use of internal silicate-enamel coatings increases the productivity of pipes, deposits do not accumulate on the pipe walls, increasing their productivity. Water resistance and pressure loss can be reduced by 1.5 times compared to uncoated pipes. The silicate-enamel coating is recommended to protect the pipe inner surface from corrosion when pumping hydrocarbons, which practically expands the market opportunities of the proposed technology [1-4].

Enameled pipelines designed to transport various liquids and gases, sometimes over very long distances, are a relatively new area of application for silicate enamels. In Russia, enameled pipes are mainly used in the oil industry and in the construction of trunk pipelines. In the past 15 years, the oil and gas industry has seen a drastic increase in the production of internally coated pipes and pipes made from corrosion-resistant materials. And that is why their connection must have the same strength, pressure tightness and corrosion resistance as the main pipe material [5-7]. The need to protect the weld is that the welded joint and the area around the weld (regardless of the type of steel, its purpose and product complexity) are the most vulnerable points for the rest of the structure. Chemical and electrochemical corrosion of welded joints are the most dangerous types of damage.

Today the following methods are used to protect welded joints of coated pipes [8-12]: slurry; protective; installation of backing rings; installation of protective sleeves; coating the inner surface of pipe joints after welding; metallization of pipe ends with corrosion-resistant metals and alloys. Therefore, the purpose of this work is the development of a technology for enameling the internal part of the steel pipeline weld with a silicate-enamel coating.

\section{Materials and Methods}

In accordance with the purpose of the work, obtaining a silicate-enamel coating was carried out on the basis of traditional raw materials used in the enameling industry. The introduction of oxides was carried out using the following raw materials: quartz sand; diatomite; boric 
acid; sodium carbonate; potassium carbonate; lithium carbonate; titanium dioxide; fluorspar; cryolite; manganese oxide; iron oxide; cobalt oxide; copper oxide; calcium carbonate; strontium carbonate; barium carbonate. To prepare the mixtures, the components were sieved, weighed on a technical scale and mixed in porcelain drums on a roller mill. To reduce losses for batch volatilization, it was slightly moistened, mixed and briquetted in metal molds on a hand press, filling it at $1 / 2-2 / 3$ of the mold height. Melting was carried out in alundum crucibles. Melting of the enamel begins with empty crucibles placed in a cold electric furnace. Then the furnace was heated to a temperature $300-400{ }^{\circ} \mathrm{C}$ below the melting temperature. Then the crucibles were removed from the furnace, the batch was poured into them and placed in the furnace. After the batch was melted and the stage of rapid gas removal was completed, the crucibles with the melt were removed, the next batch portion was added, and crucible placed back in the furnace. The filling operation was repeated several times until the crucible was filled with melt up to $2 / 3$ of its height. After complete filling, the melting temperature was set to the desired one and kept until the glass mass was completely melted. The melting completion was determined by the "test on thread", forming it by lowering a stainless-steel rod into the glass mass and then pulling it out [12-13]. The thread in completely melted enamel should be smooth, shiny, without knots and bubbles. The melted enamel was fritted into water and then dried in an oven at a temperature of no more than $100{ }^{\circ} \mathrm{C}$ to a moisture content of no more than $3 \%$. The dried frit was loaded into a porcelain drum and milled for 4-4.5 hours. In terms of phase composition, the resulting frit is an X-ray amorphous glass phase (see fig. 1).

Enamel slurries of the required fineness and composition were obtained on the basis of the obtained glass frit with the addition of the following components, wt. \% over 100: Chasovyar clay $-4.0 ; \mathrm{Na}_{2} \mathrm{~B}_{4} \mathrm{O}_{7} \cdot 10 \mathrm{H}_{2} \mathrm{O}-0.5$; $\mathrm{Na}_{2} \mathrm{CO}_{3}-0.5 ; \mathrm{NaNO}_{3}-0.1 ;\left(\mathrm{NH}_{4}\right)_{2} \mathrm{MoO}_{4}-0.08$; water - 40.0. All obtained compositions of enamel slurries were tested for the main rheological properties:

- density $\left(d_{s}, \mathrm{K \Gamma} / \mathrm{M}^{3}\right)$ was determined using a vessel with a known volume and mass, which was filled with a slurry and weighed. The density of the slurry was calculated by the formula (1):

$$
d_{s}=\left(m_{1}-m_{0}\right) / V,
$$

where $m_{1}$ - mass of the vessel with slurry, $\mathrm{kg} ; m_{0}$ - empty vessel mass, $\mathrm{kg} ; V$ - vessel volume, $\mathrm{m}^{3}$.

- the covering ability $\left(\mathrm{CA}, \mathrm{g} / \mathrm{dm}^{2}\right)$, i.e. the amount of slurry retained on a metal product surface, was determined using a steel cylinder with height of $130 \mathrm{~mm}$, diameter of $110 \mathrm{~mm}$ and wall thickness of $0.8-1 \mathrm{~mm}$ [14]. The cylinder was immersed in the test slurry, slowly removed and the excess slip was allowed to drain. Then the cylinder was weighed and the covering ability was calculated using the formula (2):

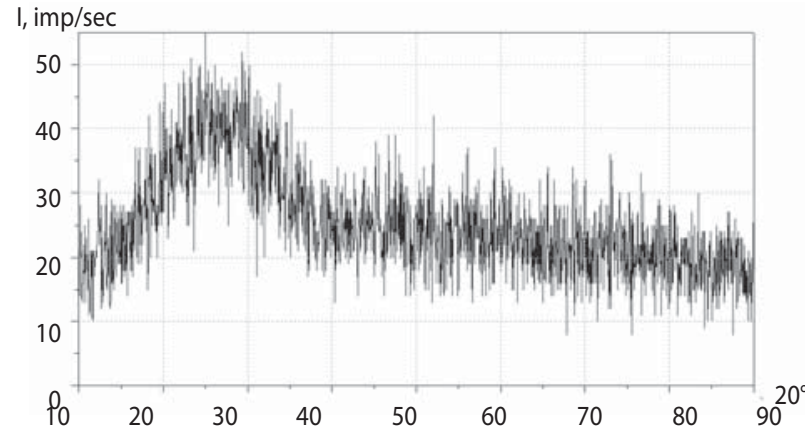

Fig. 1. Phase composition of the synthesized frit

$$
C A=\left(m_{3}-m_{2}\right) / S,
$$

where $m_{3}-$ mass of the cylinder covered with slurry, g; $m_{2}-$ clean dry cylinder mass, $\mathrm{g} ; S$ - cylinder surface area, $\mathrm{dm}^{2}$.

- the fineness of the slurry grinding (the degree of frit grinding in the slurry suspension) was estimated using the sedimentation method in the Lysenko vessel [14]. For this, sample of slurry with a mass of $10 \mathrm{~g}$ was placed in the vessel and water was added to a volume of $1000 \mathrm{ml}$. Then vessel was closed and contents were thoroughly mixed. After that the vessel was quickly set in an upright position, and the volume occupied by the enamel particles settled in the graduated tube was noted after 60 seconds. The fineness of grinding was expressed by the height of the sediment column, expressed in tenths of a millimeter [14].

- sedimentation stability of assembly pastes (resistance of system particles to settling) was estimated by the bentonite number, which is expressed as a percentage and determined by the height of the column of clarified liquid in the upper part of the volume filled with a slurry suspension after settling for 24 hours.

The enamel pastes of the developed compositions were obtained by grinding in a ball mill for 6 hours, so all components were loaded into a porcelain drum of no more than $35 \%$ of its volume with the addition of grinding porcelain bodies in the ratio "ground material : grinding bodies" from $1: 1.3$ to $1: 1.5$. Further, the enamel pastes were kept for 24 hours to reach equilibrium between the dissolved salts and clay, leach alkali from the frit and stabilize the working properties of the suspension.

The metal surface before applying the coating must be clean, free of foreign inclusions and rust, degreased to ensure good adhesion strength. To obtain such a surface, the steel was subjected to a special treatment before enameling with the composition of the solutions given

\begin{tabular}{|c|c|c|c|}
\hline Operation & $\begin{array}{l}\text { The composition of } \\
\text { aqueous solutions, \% }\end{array}$ & $\begin{array}{c}\text { Solution } \\
\text { temperature, }{ }^{\circ} \mathrm{C}\end{array}$ & $\begin{array}{l}\text { Holding } \\
\text { time, min }\end{array}$ \\
\hline Degreasing & $\begin{array}{c}\mathrm{Na}_{2} \mathrm{CO}_{3}-4.0 \\
\mathrm{NaOH}-4.0\end{array}$ & 100 & $6-10$ \\
\hline Rinsing & water & $20-25$ & $1-2$ \\
\hline Etching & $\mathrm{HCl}-20$ & $20-25$ & $5-10$ \\
\hline Rinsing & Water & $20-25$ & $1-2$ \\
\hline Neutralization & $\begin{array}{l}\mathrm{Na}_{2} \mathrm{CO}_{3}-0.6 \\
\mathrm{Na}_{3} \mathrm{PO}_{4}-0.3\end{array}$ & $85-100$ & 5 \\
\hline Drying & - & 100 & 5 \\
\hline
\end{tabular}
in Table 1. 
Prepared steel samples with a size of $59 \times 59 \mathrm{~mm}$ were processed in the sequence shown in Table 1, then dried with filter paper and placed in a desiccator for storage. Slurry was applied to the pretreated samples using pouring method. Then the samples were dried for 7-10 minutes at a temperature of $70-90{ }^{\circ} \mathrm{C}$. Fastening firing of the samples was carried out in the temperature range of $750-950{ }^{\circ} \mathrm{C}$ in an electric furnace for 5 minutes.

All obtained glass enamel coatings were tested for the following operational properties:

- the chemical resistance was assessed by the method based on the determination of the frit mass loss after exposure in acid or alkali solution heated to a temperature of $(120 \pm 2){ }^{\circ} \mathrm{C}$ and simulating the operating conditions of the products. The frit mass loss, which characterizes acid resistance, was evaluated after exposure to a boiling $20 \%$ hydrochloric acid solution for $2 \mathrm{~h}$. The frit mass loss, which characterizes alkali resistance, was evaluated after exposure to a $4 \%$ sodium hydroxide solution for $2 \mathrm{~h}$.

- the "coating - metal" adhesive strength was determined by the relative surface of the hole, which retained the adhesion layer after stepped deformation [15]. The adhesion strength was evaluated by the adhesion index $(H, \%)$, i.e. by the relative size of the surface that retained the adhesion layer according to the formula (3):

$$
H=100-S,
$$

where $S$ - the ratio of the current transmitted by the sample before and after deformation, $\%$.

- wear resistance or abrasion strength (WR, \%) was evaluated by the wear of the coating in an abrasive jet, for which the test specimen was treated for 15 min with a jet of dry sand. The sand fell on the coating freely at an angle of $22.5^{\circ}$ from a height of $1.85 \mathrm{~m}$. Wear resistance was assessed by the loss of coating mass using formula (4):

$$
W R=\left(m_{5}-m_{4}\right) \cdot 100 / m_{5}
$$

where $m_{4}-$ sample mass after abrasive treatment, $\mathrm{kg}$; $m_{5}$ - sample weight before abrasive treatment, $\mathrm{kg}$.

Each recorded test value is an average of 5 measurements.

\section{Results and Discussion}

The composition of the assembly paste as the main component should include enamel frit powder, and its chemical composition should provide not only defect-free formation during welding, but also high chemical resistance to maintain the protective function for a long service life [16]. However, the paste is melting during welding and the occurrence of defects such as bubbles, layers, burns and cracks is directly dependent on the chemical composition of the main frit and the relationship between refractory oxides and low melting point. Therefore, enamel frits with various characteristics of fusibility were chosen, their compositions are presented in Table 2.

Assembly enamel pastes were prepared on the basis of the obtained enamel frits and the optimal rheological parameters of suspensions were determined: grinding fineness according to the Lysenko vessel - 4-18 units, density $-1690-1850 \mathrm{~kg} / \mathrm{m}^{3}$, covering ability $-8-10 \mathrm{~g} / \mathrm{dm}^{2}$, sedimentation stability (bentonite number) $-92-96 \%$.

Further, a method for applying a uniform layer of assembly paste to the inner surface of the steel pipes edge was developed. In this case, the thickness and width of the paste layer should allow the melt formed from two contacting pipe parts to merge into a single coating and completely cover the weld during the welding process. The tests were carried out on enameled steel pipes 38G2SFA $55 \mathrm{~mm}$ long, $5.5 \mathrm{~mm}$ thick and $73 \mathrm{~mm}$ in diameter (hereinafter referred to as pipes). For high-quality welding, these pipe parts must have a $40^{\circ}$ bevel with a blunt edge.

As a result of research, it has been shown that the process of slurry layer forming on a pipe is most efficiently carried out using a scraper. This ensures uniform application of the enamel along the entire circumference along the edges and the same layer dimensions: height $-2.0-2.5$ $\mathrm{mm}$, width $-6-7 \mathrm{~mm}$. Slurry drying was carried out for 7-10 minutes. After drying the enamel slurry, the pipe parts were prepared for welding by cleaning with the removal of excess dry slurry.

The pipe parts were fixated and the tacks were made at three points. After that, the seam was welded in two stages: first - welding the seam root; second - welding the seam filling. The stages of pipe welding are shown in fig. 2. The enamel coating on a welding root before and after firing is shown in fig. 3 .

Welding works were carrying out until three equally stable results were obtained. Assembly pastes of three developed compositions were used, and a visual analysis of the weld quality as well as the presence of defects, was carried out after cooling. As a result, various types of defects in the weld and enamel coating were found

\begin{tabular}{|c|c|c|c|c|c|c|c|c|}
\hline \multirow{2}{*}{ Paste composition number (frit type) } & \multicolumn{8}{|c|}{ Oxide content, wt. \% } \\
\hline & $\mathrm{SiO}_{2}$ & $\mathrm{~B}_{2} \mathrm{O}_{3}$ & $\mathrm{Al}_{2} \mathrm{O}_{3}$ & $\mathrm{Na}_{2} \mathrm{O}$ & $\mathrm{K}_{2} \mathrm{O}$ & $\mathrm{Li}_{2} \mathrm{O}$ & $\mathrm{TiO}_{2}$ & $\mathrm{CaF}_{2}$ \\
\hline Composition 1 (refractory) & 66.1 & 8.7 & 2.1 & 10.3 & - & - & 7.7 & - \\
\hline Composition 2 (fusible) & 38.0 & 17.0 & 1.1 & 15.2 & 0.5 & 2.4 & 1.5 & 2.9 \\
\hline \multirow[t]{2}{*}{ Composition 3 (medium fusibility) } & 56.2 & 11.2 & 3.2 & 11.2 & 1.5 & 4.1 & 4.5 & - \\
\hline & $\mathrm{MnO}_{2}$ & $\mathrm{Fe}_{2} \mathrm{O}_{3}$ & $\mathrm{CO}_{2} \mathrm{O}_{3}$ & $\mathrm{CuO}$ & $\mathrm{CaO}$ & $\mathrm{SrO}$ & $\mathrm{BaO}$ & $\mathrm{Na}_{3} \mathrm{AlF}_{6}$ \\
\hline Composition 1 (refractory) & - & - & 0.9 & - & - & - & - & 4.2 \\
\hline Composition 2 (fusible) & 7.0 & 5.0 & 1.3 & - & 2.4 & 3.0 & 2.7 & - \\
\hline Composition 3 (medium fusibility) & 2.6 & 1.0 & 1.0 & 0.5 & - & - & - & 3.0 \\
\hline
\end{tabular}
(fig. 4). 


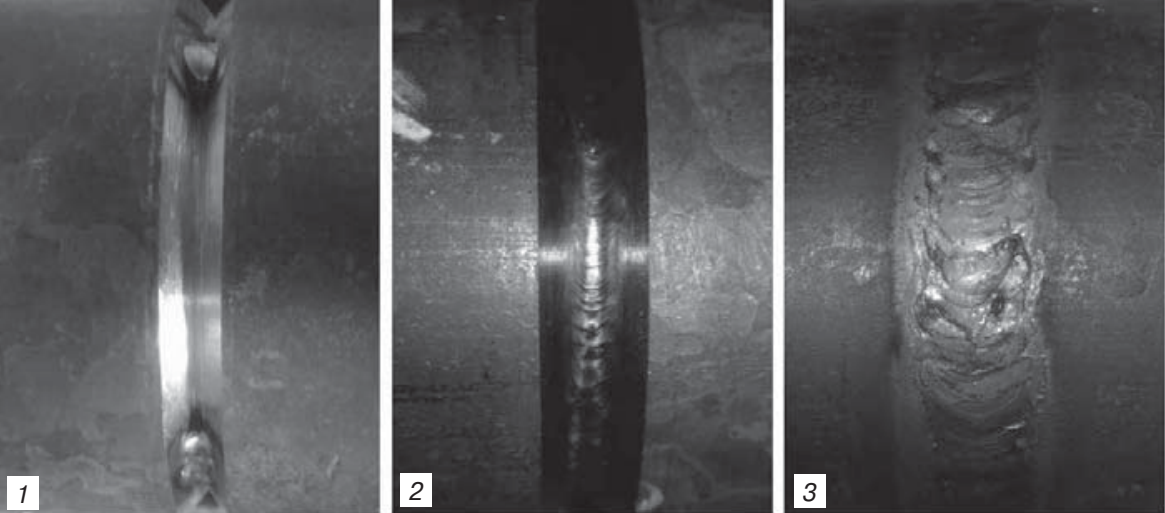

Fig. 2. Creation of weld: $1-$ tack; $2-\operatorname{root} ; 3$ - filling

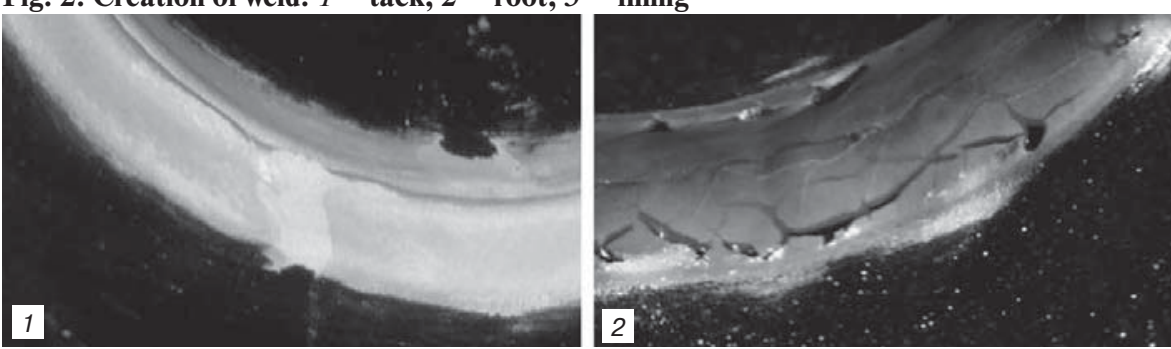

Fig. 3. Enamel coating after root welding: 1 - before firing; 2 - after firing
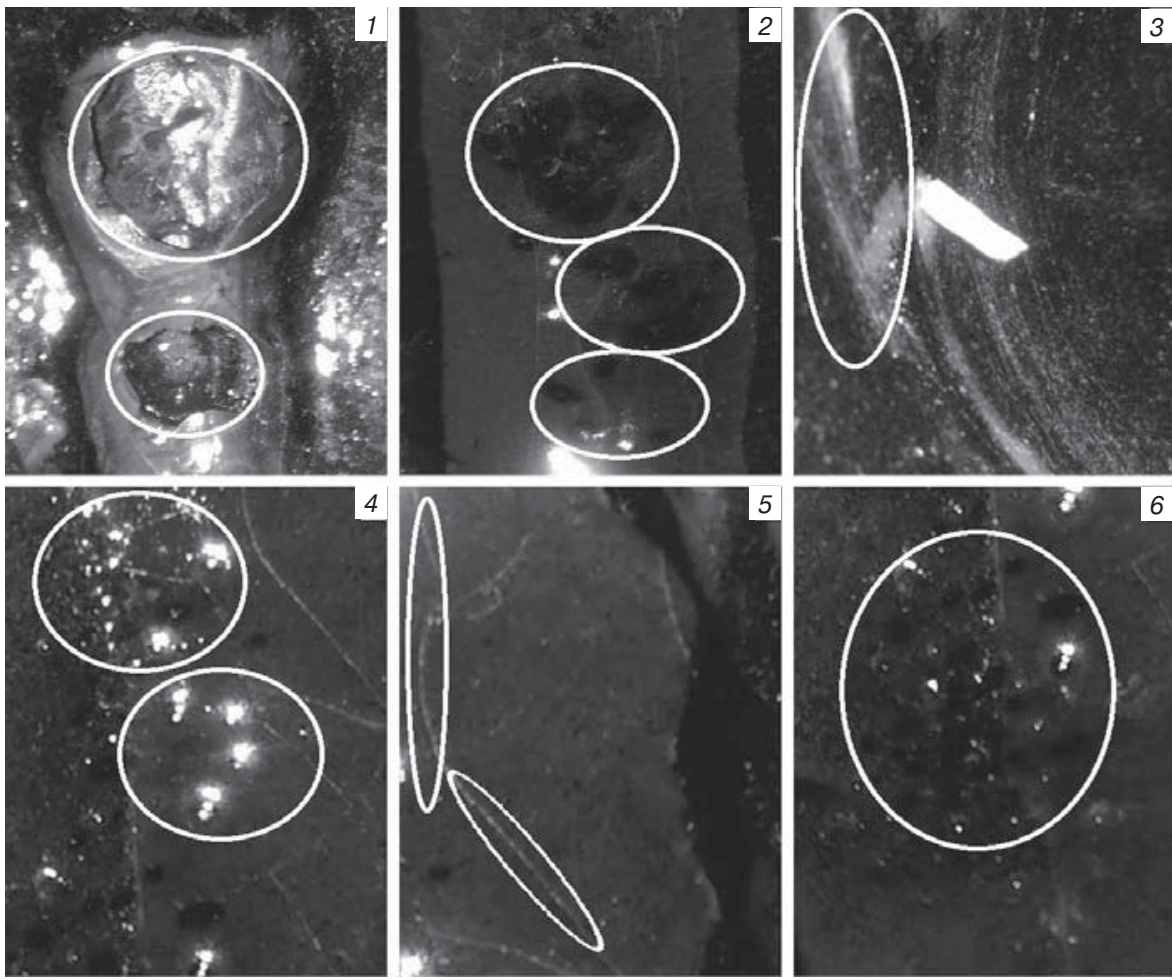

Fig. 4. Types of coated weld defects:

1- unfused bubble craters with bare metal; 2 - "copper heads"; 3 - crumbling of the roller; 4 - bubbles; 5 - microcracks of the enamel coating; 6 - unfused bubble craters

\begin{tabular}{|c|l|}
\hline Table 3. Qualitative characteristics of the enamel coating on the weld \\
\hline Composition № & \multicolumn{1}{|c|}{ Qualitative characteristics of the enamel coating } \\
\hline 1 & $\begin{array}{l}\text { Unfused bubble craters, unfused bubble craters } \\
\text { with bare metal, "copper heads", bubbles }\end{array}$ \\
\hline 2 & $\begin{array}{l}\text { Crumbling of the roller, bubbles, microcracks of the } \\
\text { enamel coating }\end{array}$ \\
\hline 3 & Complete enamel melting, no visible defects \\
\hline
\end{tabular}

It was found that "copper heads" and small bubbles do not breakdown in the enamel coating without additional heating of the weld zone, which means that they are in the coating volume and do not affect its quality. The results of determining the qualitative characteristics of the enamel coatings, such as the presence of discontinuity, obtained using three compositions of assembly pastes are presented in Table 3.

Based on the results obtained, composition 3 was chosen as the optimal paste composition, which is characterized by the following advantages:

- complete melting of the enamel;

- absence of "copper heads";

- absence of craters from nonfused bubbles, as well as small bubbles in the enamel volume, caused by steel oxidation during the welding process;

- absence of burnouts.

Further, the main technical and operational properties of protective coatings for the welded seam of pipes were investigated: thickness, chemical resistance, adhesion to metal and wear resistance of the coating, presented in Table 4. It should be borne in mind that the corrosion rate of metal pipes under the coating also depends on many other factors: the presence of oxygen and electrolyte under the coating, the level of passivation and surface heterogeneity, the chemical composition of the medium, pressure, temperature, the presence of inhibitors, the rate of removal of reaction products, the presence of stray currents, etc. However, these properties strongly depend on the composition of the pipe, the type of transported substances, soil properties, etc., therefore, they were not studied in this work.

\begin{tabular}{|l|c|}
\hline \multicolumn{2}{|c|}{ Table 4. Properties of the enamel coating on the weld } \\
\hline \multicolumn{1}{|c|}{ Property } & Value \\
\hline Thickness of the enamel coating on the weld, $\mu \mathrm{m}$ & $250-300$ \\
\hline Chemical resistance to $20 \% \mathrm{HCl}$ solution, $\mathrm{mg} / \mathrm{cm}^{2}$ & 0,61 \\
\hline Chemical resistance to $4 \% \mathrm{NaOH}$ solution, $\mathrm{mg} / \mathrm{cm}^{2}$ & 1,53 \\
\hline Adhesion strength with metal, \% & 83,25 \\
\hline Wear resistance, $\%$ & 2 \\
\hline
\end{tabular}


The obtained properties were compared with the requirements of Russian State Standard GOST R 525692006 "Frits. Technical conditions". This standard specifies requirements for the chemical resistance and wear resistance of the coating. In terms of chemical resistance to acids (no more than $0.65 \%$ ) and alkalis (no more than $1.6 \%)$, the coating meets the requirements of GOST. In terms of wear resistance (no more than $5 \%$ ), the coating significantly exceeds the requirements. The thickness of the coating and the strength of its adhesion to the metal are not regulated by the standard, however, they play a very important role in the coating formation. The optimum thickness of the coating should be in the range of $150-450 \mu \mathrm{m}$, this thickness contributes, on the one hand, to sufficient protection of the metal, and, on the other hand, prevents the temperature gradient in the coating and its possible breakaway. The adhesion strength of the coating characterizes the reliability of the coating fastening to the metal and should be at least $70 \%$. Thus, the synthesized coating demonstrates high protection rates, high durability and reliability.

\section{Summary}

The weld is the most vulnerable part of the pipeline structure. Various methods are used to protect it, and the use of silicate-enamel coatings is very promising among them. In this study, the technology of applying and fixating the coating on the weld is considered, as well as the properties of the resulting coating. Frits of three compositions were synthesized and, assembly pastes on their basis were developed for application at steel pipe welds. The optimal rheological parameters of the assembly enamel suspensions were described, which ensure high-quality application and uniform formation of the enamel coating on the weld. The qualitative characteristics of the enamel coatings in the contact zone after welding were determined. It was found that assembly enamel paste based on frit No. 3 is capable of defect-free melting during welding, the chemical composition of which provides optimal characteristics during formation and high mechanical and chemical resistance.

\section{Acknowledgements}

The work was supported by the Russian Science Foundation, Project \# 18-19-00455 "Development of integrated protection technology for oil and gas pipelines, operated in the Far East of Russia" in the framework of the 2018 competition "Conducting fundamental scientific research and exploratory scientific research by individual scientific groups".

\section{REFERENCES}

1. Zaretskaya M. I. Devices of control systems for coating the inner surface of pipes: thesis ... cand. techn. sci. Samara. Samara State Aerospace University named after S. P. Korolev, 2013. 163 p.

2. Rossi S., Fedel M., Deflorian F., Parziani N. Abrasion and chemical resistance of composite vitreous enamel coatings with hard particles. Surface and Interface Analysis. 2016. Vol. 48 (8). pp. 827-837.

3. Frolenkov K. Y., Tsymai D. V. The effect of structural and energy parameters of glassy melts on the protective performance of coatings made of these glassy melts. Protection of Metals and Physical Chemistry of Surfaces. 2015. Vol. 51 (5). pp. 835-841.

4. Yatsenko E. A., Goltsman B. M., Ryabova A. V., Smoliy V. A., Klimova L. V. Integrated protection of pipelines using silicate materials. International Multidisciplinary Scientific GeoConference Surveying Geology and Mining Ecology Management, SGEM. 2019. No. 19 (5.2). pp. 507-514.

5. Kochetov D. M., Shapurov V. S. Corrosion of oil production equipment and problems of industrial safety. Neftedobycha. 2016. No. 4. pp. 22-24.

6. Revie R. W., Uhlig H. H. Corrosion and Corrosion Control: An Introduction to Corrosion Science and Engineering: Fourth Edition. Hoboken New Jersey: John Wiley \& Sons, Inc. 2008. 490 p.

7. Wang J., Yuan Y., Chi Z., Zhang G. High-temperature sulfur corrosion behavior of h-BN-based ceramic coating prepared by slurry method. Materials Chemistry and Physics. 2018. Vol. 206. pp. 186-192.

8. Novikov S. V., Rodomakin A. N., Gumerov K. M. Problems of protection of welded joints of pipelines with coating and methods of their solution. Problema sbora, podgotovki i transporta nefti $i$ nefteproduktov. 2009. No. 1 (75). pp. 62-67.

9. Mezinskis G., Pavlovska I., Malnieks K. et al. Sol-gel coated enamel for steel: 250 days of continuous high-temperature stability. Ceramics International. 2017. Vol. 43 (3). pp. 2974-2980.

10. Wang J., Yuan Y., Chi Z., Zhang G. Development and application of anti-fouling ceramic coating for high-sodium coal-fired boilers. Journal of the Energy Institute. 2018. Vol. 91. Is. 6. pp. 962969.

11. Kim M. T., Chang S. Y., Won J. B., Park H. W. Effect of hot isostatic pressing on the microstructure and mechanical properties of vitreous enamel coatings on low carbon steel. Surface and Coatings Technology. 2006. Vol. 201. Iss. 6. pp. 3281-3288.

12. Petzold A., Peschman G. Enamel and enameling. Moscow: Metallurgiya. 1990. 398 p.

13. Yatsenko E. A., Ryabova A. V., Goltsman B. M. Development of fiber-glass composite coatings for protection of steel oil pipelines from internal and external corrosion. Chernye Metally. 2019. No. 12. pp. 46-51.

14. Enameling of metal products. Edited by Vargin V. V. Leningrad: «Mashinostroyeniye». 1972. 496 p.

15. Tkachev A. G., Kushnarev A. S., Kozyarskiy A. Ya. Technology of enamel and protective coatings: tutorial. Novocherkassk: Novocherkassk State Technical University. 1993. 107 p.

16. Yatsenko E. A., Goltsman B. M., Ryabova A. V. The study of the microstructure of glass composite coatings to protect steel pipelines against internal and external corrosion. Chernye Metally. 2020. No. 4. pp. 50-55. 